A typical spring has been taken as a representative of each of the localities, but these form only a very small proportion of the total number. Thus at Barèges there are upwards of a dozen springs; at Luchon there are nearly thirty; at Eaux Chaudes six; at Eaux Bonnes six; at Canterets thirtcen; and at St. Sauveur certainly two or three. There are differences in the compositions of these sereral waters, and the local practitioners profess to be able to select the cases which are best treated at each of them, and make the most of the milligrammes and fine shades of temperature which constitute the differences.

At Bigorre there are a great many different springs, the majority of which belong to the group of saline waters, the chicf saline ingredient, however, being sulphate of lime. These should properly be classed among indifferent waters. There are a few sulphurous springs also, the chief of which is that called Labassère.

It will be noticed that the analyses make mention of organic matter found in the springs, which is generally present in considerable quantities. This organic matter collects in the reservoirs and conduits through which the water is brought on its way to the baths and drinkingfountains, and seems to be spoken of by various authors under the names of "Barégine," "Glairine," or "Sulfurine." These names would lead the unwary to suppose that this organic substance is the active principle of the water, and, indeed, we find it so spoken of in more than one monograph, and notably in the advertisement of the Barèges waters, which says :-_" Cette barégine donne aux eaux de Barèges une onctuosité particulière, que est un des éléments de leur efficacité thérapeutique." The director of the bathing establishment at Barèges very kindly ordered one of the attendants to collect for me a sample of this so-called barégine, and in a very short time after the order was given $I$ was furnished with as much as could be put in a half-pint bottle. To the naked eye it looked slimy, and was of a grey-greenish tint, with here and there portions which were nearly black. It felt like mucus, and under the microscope was found to be composed of the filaments and reproductive organs of various algx. These algæe must be regarded as purely accidental, and are merely due to the fact that the sulphurous waters form a suitable nidus for their propagation. The growth of algæ in the water of hot sulphur springs has been noticed elsewhere than in the Pyrenees. In the fourteenth volume of the Journal of the Linnæan Society will be found an interesting paper by Mr. H. N. Moseley, F.R.S., who accompanied the Challenger expedition in the capacity of naturalist, "On Fresh-water Algæ obtained at the Boiling Spring at Furnas, St. Michael's, Azores, and their neighbourhood." The whole group of the Azores is pronounced to be decidedly volcanic in character, and in the largest island of the group (St. Michael's) hot springs abound in many parts, but notably at the western extremity of the island in the valley of $F$ urnas, where are situated the boiling fountains known as the Caldeiras, which have enjoyed for a considerable period no little reputation for their curative action upon palsy, rheumatism, scrofula, and similar maladies. Mr. Moseley describes how he cut away portions of a vegetable deposit from the sides of some of the boiling springs, in situations where the heat of the water was so intense that great care was necessary not to scald the hands while collecting it. These hot waters contained an abundance of silphuretted hydrogen. Mr. Moseley estimates the temperature of the water in which the algæ were found to have been from $149^{\circ} \mathrm{F}$. to $158^{\circ} \mathrm{F}$. This estimate was made by dipping the finger in the water, since unfortunately he had no thermometer with him at the time of his visit. Near the margin of the lake of Furnas are several spots where hot gas, charged with sulphuretted hydrogen, is discharged through the water, and, curionsly enough, the alga were found to grow more luxuriantly in the immediate neighbourhood of these discharges.

The alga peculiar to the Pyreneean sulphur springs has been described by Camille Montagne in the ninth volume (Botanique) of the "Annales des Sciences Naturelles," and has been named by him Leptomitus sulphurarius. It is said to grow especially in waters having a temperature between $50^{\circ} \mathrm{F}$. and $100^{\circ} \mathrm{F}$. It cannot exist without exposure to air, and sulphur seems also to be indispensable to its proper development, as well as an azotised substance dissolved in the water. An alga of a very similar description has been found growing in the hot water of Carlsbad, but it has been decided not to be precisely similar to that which constitutes barégine. Not only do vegetables flourish in these sulphurous waters, but animals as well, and many species of anguillnla have been discovered by various observers in the waters of Barèges and other bathing resorts of the Pyrenees.

It is much to be regretted that a nonsensical and misleading name has been given to the aggregate growths which occur in these sulphur waters. There is no evidence whatever that they have any part in the therapeutic value of the waters, and it is very undesirable that a word should be retained which, in our present state of knowledge, not only savours of quackery, but is undoubtedly used for quackish purposes. Another regrettable fact is the part which limited companies are beginning to play in the management of mineral springs. It has been discovered that a spring of water, if it be sufficiently puffed, is a surer and more valuable source of income than a gold mine, and the statements put forward in advertisements are very often absolutely unwarrantable. It is desirable that the profession on the Continent, and especially in France, should unite for the purpose of restraining the statements of those who have merely a money interest in mineral springs, for it will become exceedingly difficult to prescribe this or that water if, by so doing, one should seem to countenance the unwarrantable assertions which are made concerning them. It would be satisfactory if such rash assertions were made only by the trading companies, but this, unfortunately, is not the case, for many of the medical monographs appear to show a very undue amount of local bias, and to lend a too ready credence to startling therapeutic theories. It would be a great boon if the examination of the mineral springs of Europe could be made by an international commission, which should be entirely without interest in the popularity or earnings of any particular spring.

Looking once more to the nature of the waters, we see that there is only one ingredient - the sodium sulphide - which can fairly be credited with any therapeutic value, and if catalogued in the order of their sulphide strength they would read thus-Luchon, Labassère (Bigorre), Barèges, Cauterets, St. Sauveur, Eaux Bonnes, Eaux Chaudes. The amount of sulphides contained even in the strongest of them is but small-so small as to call forth the remark from Braun ("Curative Effects of Baths and Waters," p. 419, Weber's translation) that "only a few of them contain an amount which admits the possibility of the effect of sulphuretted hydrogen." The writer can see no reason for this opinion; for there is no more difficulty in believing in the therapeutic effect to be derived from a tenth or a quarter of a grain of sodium sulphide than in that which is known to result from the thirtieth of a grain of phosphorus or a twelfth of arsenious acid. The chief use of sulphur water, according to Braun, is for treating "stasis of the portal system," and conditions which are secondary thereto, and he seems to have no knowledge of their very great utility in combating the various manifestations of a scrofulous diathesis. It is equally remarkable that Birch-Hirschfeld, in his treatise on Scrofulosis in Ziemssen's Encyclopædia, makes no mention of the sulphides in the sections devoted to treatment.

(To be concluded.)

\section{ON THE TREATMENT OF CONGENITAL TALIPES EQUINO-VARUS AFTER THE PERIOD OF INFANCY.}

BY HENRY F. BAKER, F.R.C.S. EDIN., LATE HOUSE-SURGEON TO ST. BARTHOLOMEW'S HOSPITAL.

THE treatment of congenital talipes equino-varus, after the period of infancy, may be conveniently divided into three parts-Ist. The cure of the simple infantile varus occasioned only by the contraction of the tibialis posticus, flexor longus digitorum, and the tibialis anticus. 2nd. The cure of the remaining acquired varus, caused by the contraction of the abductor pollicis, plantar fascia, and the various ligaments connected with the misshapen bones of the tarsus. 3rd. The equinus caused by the contracted tendo Achillis.

With regard to the treatment of the first part, after the successful division of the tendons mentioned above, the best 
instrument is, undoubtedly, a well-padded outside splint, to which the foot is gradually drawn by means of an ordinary bandage. When as great a part as possible of the varus has been removed by these simple means, the second part will still remain; and this is, of all, the most difficult to successfully overcome, even after the complete division of the abductor pollicis and the plantar fascia, chiefly on account of the great danger of producing sloughs by such an amount of pressure as will suffice to correct the deformity. The common Scarpa's shoe, useful as it is in some forms of talipes, is quite useless here. Scarpa, indeed, invented a special instrument for the purpose, but it is almost impossible to use it without causing sloughs. In more modern times, also, many very clever instruments have been devised with the same object in view, but in practice they have proved only partially successful.

For the efficient application of force in overcoming the resistance formed by the contracted tissues on the concave aspect of the deformed tarsus, the fulcrum must, I believe, be placed on some part of its convexity, and as near as possible to its most projecting point; the internal tubercle of the os calcis being made a fixed point, and the power being represented by the tension of a strap placed round the ball of the great toe. The problem therefore to be solved is-How can the fulcrum be applied in this position for the required length of time without causing sloughs? -and it appears to me that the only method is by rendering it a movable one. In other words, the pad which forms the fulcrum, instead of being a fixed part of the splint, should be unconnected with it, and thus made capable of being shifted from point to point along the outer edge of the tarsus, as circumstances require. The instrument which $I$ have devised for carrying this into execution is figured below (Fig. 1). The figure re-

Fig. 1.

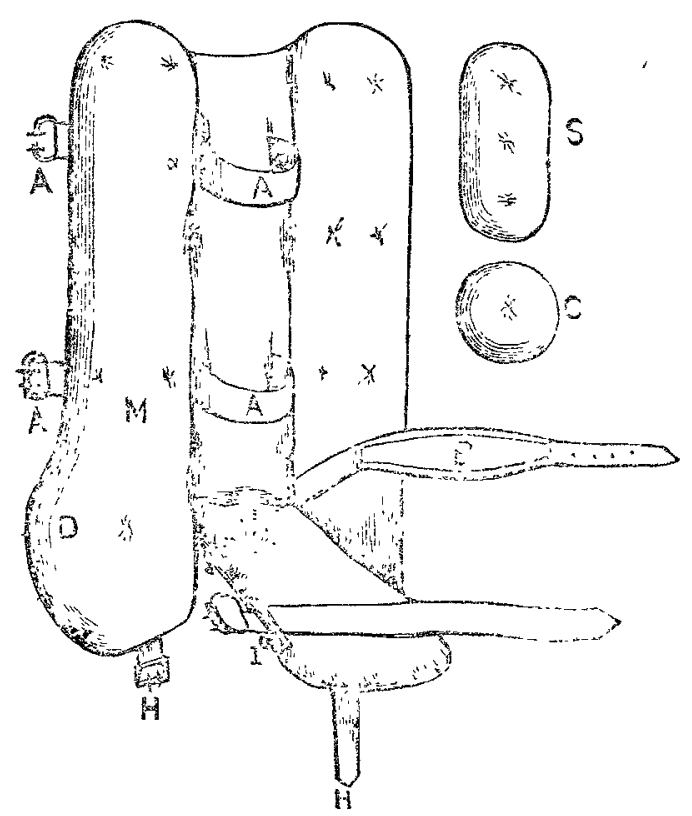

presents the instrument open, and it will be seen to consist of a back-splint, connected with a foot-piece by means of a cog-wheel, $\mathbf{K}$, at the heel, and having hinged to it two wings which extend well below the foot-piece, and have a buckle and strap, $\mathrm{H}$, attached to their lower ends. A A are two webbing straps introduced through slots, to fix the leg firmly. $B$ is a leather ankle-strap, wide and padded in the centre, to fix the heel immovably in its position; it is attached to a buckle at the back. $D$ is a plate attached to the external wing; and $c$ is the pad, or movable fulcrum, to be placed beneath it, and to press on the projection at the outer side of the foot. I is a rigid bar for carrying the toe-strap.

Fig. 2 represents the instrument in action. The leg is firmly held to the back-splint by the straps A A. The heel is kept in place by strap $\mathrm{B}$, and the movable pad $\mathrm{C}$ is adjusted. The wings are brought together, and firmly fixed by the further action of the straps A A, and strap $\mathrm{H}$; and the toe-strap is then tightened, and the cog-wheel, $\mathrm{K}$, screwed up. By simply loosening the toe-strap, the pressure is at once relieved if this should be found necessary, as is frequently the case at night, when the foot becomes hot; and in a day or two, the wings being thrown back, but the foot not being disturbed, the pad, c, may be slightly shifted.

FIG. 2.
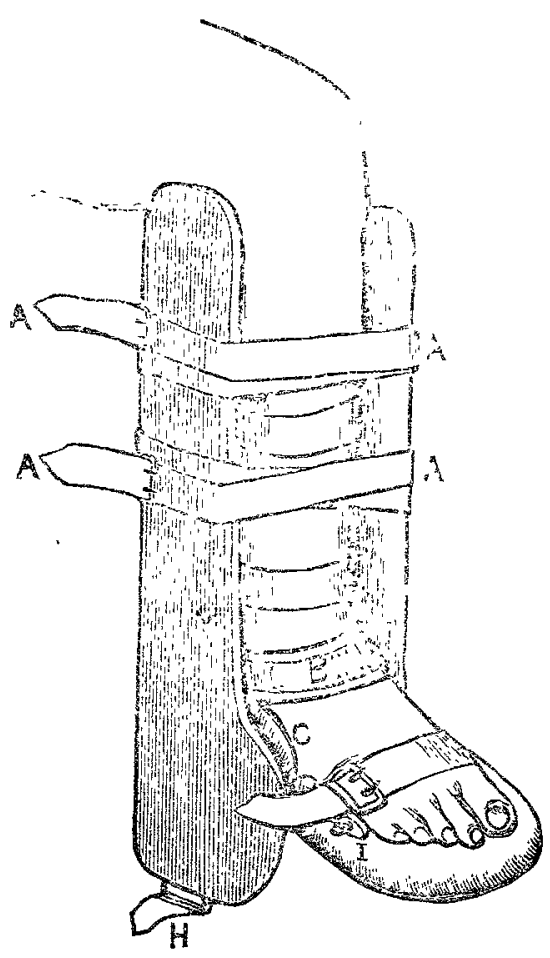

In some cases it will be found convenient to introduce the rectangular pad, s (Fig. 1), within the external wing at $M$, and so place the fulcrum on the outside of the leg; but this materially diminishes the power of the instrument.

This splint is equally well adapted for carrying out the third stage of the treatment-viz., correcting the equinus after the division of the tendo Achillis; and in some cases it can be used for this purpose before the second period of the cure of the varus is quite completed.

A varus splint, constructed in some respects like the one described, was devised by the late Mr. Tamplin, and has been in use at the Royal Orthopodic Hospital for many years in the treatment of infantile varus, for which it is well adapted. It fails, however, altogether in the treatment of those more difficult cases of acquired tarsal deformity which are the subject of the present communication. The special points in which the splint here suggested differs from Mr. Tamplin's are-(1) the addition of an inner wing; (2) the projection of both wings well below the foot-plate, with connecting strap; (3) the rigid toe-bar attached to the sole-plate ; $(4)$ the leather padded ankle-strap ; and (5)-the most important of all-the movable pad which forms the fulcrum.

If it should be thought advisable to combine the use of a spring or elastic pressure, this can be at once done by placing a steel spring in the position of the rigid toe-bar, or an elastic toe-strap in the place of the one made of common webbing. Neither of these alterations, however, would be, in my opinion, an improvement.

I may mention that the instrument has been made for me by Mr. Gumpel, of Leicester-square; and I take this opportunity of acknowledging the very efficient manner in which my suggestions have been carried out.

Hanover-square.

Bequests \&C. to Medical Charities.-The Lundon Fever Hospital has received $£ 1000$ anonymously. The Stewart Institution for Imbecile Children, Palmerstown, Dublin, has received $£ 300$ under the will of Mrs. M. Roe. The Salop Infirmary, Shrewsbury, has received $\mathfrak{f 1 0 0}$ under the will of Mr. Robert Hughes, of Newport, Salop. The Grocers' Company have given a seventh $£ 50$ to the general funds of the Victoria Hospital for Children at Chelsea, and $£ 25$ towards laying out and ornamenting the garden. The Goldsmiths' Company have given $£ 200$ to the Roval London Ophthalmic Hospital, and $£ 100$ to the General Lying-in Hospital, York-road, Lambeth. 